\title{
Yi-qi-yang-yin-tang increases the sensitivity of KG1a leukemia stem cells to daunorubicin by promoting cell cycle progression and regulating the expression of PTEN, TOPOII and mTOR
}

\author{
ZHE-XIN SHI ${ }^{1}$, HONG-YU LI ${ }^{2}$, XIANG-DONG YANG ${ }^{1}$, HONG GAO $^{1}$, \\ DE-GUAN LI ${ }^{3}$, WEN-HUA YANG ${ }^{1}$, FANG YAO ${ }^{1}$ and LI-XIANG YAN ${ }^{1}$ \\ ${ }^{1}$ Department of Hematology, First Teaching Hospital of Tianjin University of Traditional Chinese Medicine, Tianjin 300381; \\ ${ }^{2}$ Tianjin University of Traditional Chinese Medicine, Tianjin 300193; \\ ${ }^{3}$ Tianjin Key Laboratory of Radiation Medicine and Molecular Nuclear Medicine, Institute of Radiation Medicine, \\ Academy of Medical Science and Peking Union Medical College, Tianjin 300192, P.R. China
}

Received September 9, 2015; Accepted July 14, 2017

DOI: $10.3892 / 01.2017 .7067$

\begin{abstract}
The present study aimed to investigate the effects of serum containing a combination of yi-qi-yang-yin-tang (YQYYT) and daunorubicin (DNR) on multidrug resistance in KG1a leukemia stem cells (LSCs). The effects of YQYYT and DNR on proliferation, cell cycle progression and the expression of phosphatase and tensin homolog (PTEN), topoisomerase II (Topo II) and mechanistic target of rapamycin (mTOR) in KG1a cells were investigated in vitro using cell counting kit- 8 assay, flow cytometry, reverse transcription-quantitative polymerase chain reaction and western blotting, respectively. It was revealed that YQYYT-containing serum did not affect proliferation of KGla cells compared with the blank group. Furthermore, there were no significant differences on the inhibition of proliferation among different groups at various concentrations of YQYYT. Treatment with YQYYT-containing serum (volume, 20 and $40 \mu \mathrm{l}$ ) and DNR was able to significantly inhibit the proliferation of KG1a cells compared with the blank group. The inhibition rate in the treatment group with YQYYT-containing serum (40 $\mu \mathrm{l})$ and DNR for $48 \mathrm{~h}$ (72.5\%) was higher compared with treatment for $24 \mathrm{~h}(60.4 \%$, $\mathrm{P}<0.01)$. Treatment with YQYYT-containing serum was able to promote $\mathrm{G}_{0}$ phase of KGla cells into cell cycle in a doseand time-dependent manner, and significantly upregulated the mRNA expression of PTEN and Topo II, but did not affect mTOR expression compared with the blank group. Treatment with serum containing YQYYT alone did not directly affect
\end{abstract}

Correspondence to: Dr Zhe-Xin Shi, Department of Hematology, First Teaching Hospital of Tianjin University of Traditional Chinese Medicine, 88 Changling Road, Xiqing, Tianjin 300381, P.R. China E-mail: shzhx0604@163.com

Key words: yi-qi-yang-yin-tang, leukemia stem cell multidrug resistance, cell cycle, phosphatase and tensin homolog, topoisomerase II the proliferation of KGla cells, but when the cells were treated with a combination of YQYYT-containing serum and DNR, the proliferation of KG1a cells was significantly inhibited in a dose- and time-dependent manner. Furthermore, treatment with YQYYT-containing serum was able to promote cell cycle progression of KGla cells in the $\mathrm{G}_{0}$ phase and upregulate the expression of the negative regulatory genes PTEN and Topo II. These results indicated the potential of YQYYT to reverse multidrug resistance in LSCs.

\section{Introduction}

Leukemia stem cells (LSCs) are similar to normal hematopoietic stem cells (HSCs) but with self-renewal capacity and differentiation potential (1). Although the number of LSCs is limited, they have a critical role in leukemia resistance, relapse and prognosis. Recent reports indicate that leukemia can be considered as a rare and abnormal form of hematopoiesis induced by cancer stem cells or LSCs. Moreover, stem cells can maintain or obtain unlimited proliferative capacity through the accumulation of mutations and/or changes in epigenetic regulation of genes (2). Increasing evidence shows that LSCs have an important role in resistance to chemotherapy drug-induced cell death and in leukemia relapse (3). LSCs exhibit a number of resistance mechanisms observed in HSCs, which allow the transport of chemotherapeutic agent out of the cells via transporters to avoid cytotoxic effects (4). Furthermore, it has been shown that $95 \%$ of LSCs are in the $\mathrm{G}_{0}$ phase, where cells rarely proliferate (5), therefore avoiding the cytotoxic effects of the chemotherapeutic agents. Additionally, some other rare subpopulations of LSCs (such as CD34 + CD38-phenotype) can enter the cell cycle, differentiate and proliferate into new leukemia cells following appropriate stimulation, therefore inducing the incidence of refractory or relapsed leukemia (6). Phosphatase and tensin homolog (PTEN) can inhibit mechanistic target of rapamycin (mTOR) activity via negative regulation of the phosphatidylinositol 3-kinase (PI3K)/Akt signaling pathway, therefore inhibiting proliferation of cancer cells, promoting apoptosis 
and reversing multidrug resistance (7). DNA topoisomerase II (Topo II) is the target of anthracycline chemotherapeutic drugs (topoisomerase inhibitors), which inhibit cell replication by inhibiting DNA annealing following binding with Topo II (8).

The KGla leukemia cell line expresses high levels of cluster of differentiation (CD)34, therefore exhibiting the main biological characteristic of LSCs. Yi-qi-yang-yin-tang (YQYYT) is the decoction of Chinese medicine, according to the theory of TCM syndrome differentiation, in which the combination of drugs have activating, excitement and promotion effects in the theory of Traditional Chinese Medicine. Therefore, it was speculated that YQYYT is able to activate LSCs, upregulate expression of negative regulatory genes, increase the sensitivity of chemotherapy drug targets, reverse multidrug resistance and clear residual LSCs in patients. YQYYT may be a new strategy for the clinical treatment of leukemia.

In the present study, the KGla cell line was used to investigate the role of YQYYT-containing serum on LSC proliferation and cell cycle progression, and on the levels of mRNA and protein expression of PTEN, Topo II and mTOR.

\section{Materials and methods}

Experimental animals. A total of 20 adult male New Zealand white rabbits (5 weeks old; weight, 2.2-2.5 kg) were purchased from Beijing Huafukang Biotechnology Ltd., (Beijing, China), and were housed in an air-conditioned room at $25^{\circ} \mathrm{C}$ with a 12-h dark/light cycle (specific-pathogen-free conditions) at the Institute of Radiation Medicine, Chinese Academy of Medical Sciences (Tianjin, China). The rabbits received humane care with unlimited access to food and water during the present study. Ethical approval was obtained from Tianjin University of Traditional Chinese Medicine (Tianjin, China).

YQYYT preparation. A water decoction of YQYYT was prepared at the Laboratory of Traditional Chinese Medicine Preparation, the First Affiliated Hospital of Tianjin University of Traditional Chinese Medicine (Tianjin, China). The water decoction of YQYYT $(1 \mathrm{~g} / \mathrm{ml})$ was prepared from the following combination of Chinese medicines: $30 \mathrm{~g}$ astragalus (Leguminosa, Astragalus L.), $10 \mathrm{~g}$ ginseng (Araliaceae, PanaxLinn L.), $15 \mathrm{~g}$ Ligustrum lucidum (Oleaceae, Ligustrum L.), $15 \mathrm{~g}$ Eclipta (Composite, Eclipta L.), $10 \mathrm{~g}$ Angelica (Umbelliferae, Angelica L.), $10 \mathrm{~g}$ Atractylodes (Composite, Atractylodes L.), $10 \mathrm{~g}$ poria (Polyporaceae, Wolfiporia L.) and $10 \mathrm{~g}$ licorice (Papilionoideae, Glycyrrhiza L.). All the herbs were provided by The First Affiliated Hospital of Tianjin University of Traditional Chinese Medicine (Tianjin, China). The solution was placed into an infusion bottle $(250 \mathrm{ml})$, and sterilized at $105^{\circ} \mathrm{C}$ under circulation steam. High performance liquid chromatography (HPLC) fingerprint analysis was performed to quantify the components in the water decoction of YQYYT (Fig. 1).

Serum preparation. Male Adult New Zealand white rabbits $(n=20)$ were randomly divided into treatment and control groups, with 10 rabbits in each group. Rabbits in the treatment group received the water decoction of YQYYT (10 $\mathrm{ml}$ twice each day) by gavage for 3 days, while rabbits in the control group received saline. At $2 \mathrm{~h}$ following the last drug administration, $3 \%$ sodium pentobarbital was given to anesthetize the rabbits, and cardiac blood samples were collected. The serum was separated and filtered for distribution and stored at $-20^{\circ} \mathrm{C}$. Gavage method was performed as follows. The animals were fixed and the opening device was fixed between the upper and lower incisors. The tube was then inserted into the mouth of the animal from the mouth of the mouthpiece and into the esophagus along the posterior wall of the pharynx. After insertion, the gastric canal should be checked for insertion into the esophagus. The outer opening of the gastric tube can be placed in the beaker of the water, and if no bubbles are produced, it indicates that the gastric tube is inserted into the stomach properly and that the trachea has not strayed into the trachea. The syringe was then connected to the tube and injected into the solution.

Cell culture. KG1a cells (obtained from the Institute of Hematology, Chinese Academy of Medical Sciences, Tianjin, China) were cultured in RPMI-1640 medium (HyClone; GE Healthcare, Chicago, IL, USA) containing $10 \%$ fetal bovine serum (Gibco; Thermo Fisher Scientific, Inc., Waltham, MA, USA), $100 \mathrm{U} / \mathrm{ml}$ penicillin and $100 \mathrm{U} / \mathrm{ml}$ streptomycin (HyClone; GE Healthcare, Chicago, IL, USA) at $37^{\circ} \mathrm{C}$ under $5 \% \mathrm{CO}_{2}$ and saturated humidity. The cells were passaged into fresh culture medium every 2-3 days. The cells in the logarithmic growth phase were used in experiments.

Cell Counting Kit-8 (CCK-8) assay. KG1a cells in the logarithmic growth phase were adjusted to a density of $1 \times 10^{5} / \mathrm{ml}$, seeded in 96-well culture plates $(100 \mu \mathrm{l} /$ well $)$, and then divided into experimental and control groups. Different volumes of YQYYT-containing serum $(0,5,10,20$ and 40, 20, 10, 5 and $0 \mu \mathrm{l}$ ) were added to the experimental group, whereas the corresponding volume of rabbit serum was administered to the control group. RPMI-1640 medium was added so that the final volume of each well is $200 \mu 1$. Each group was tested at least in triplicate. The cells were cultured at $37^{\circ} \mathrm{C}$ under $5 \% \mathrm{CO}_{2}$ and saturated humidity for 24,48 and $72 \mathrm{~h}$. Subsequently, $10 \mu \mathrm{l}$ CCK-8 reagent (Tianjin Solomon Biotechnology Co., Ltd., Tianjin, China) was added into each well, and the samples were incubated for a further $2 \mathrm{~h}$ at $37^{\circ} \mathrm{C}$. The absorbance (OD) value was measured at room temperature using multi-function enzyme-labeling measuring instrument (Thermo Fisher Scientific, Inc.) at $450 \mathrm{~nm}$. The proliferation rate was calculated as follows: Proliferation rate $(\%)=(1$-experimental group OD/control group OD) x $100 \%$.

The cells were cultured as aforementioned. The cells were divided into blank group, daunorubicin (DNR), rabbit serum control and serum containing YQYYT groups (5, 10, 20 and $40 \mu \mathrm{l}$; made up to $100 \mu \mathrm{l}$ with medium). RPMI-1640 medium $(100 \mu \mathrm{l})$ was added to the blank and DNR groups. The final volume in each well was $200 \mu 1$. Each group was set up at least in triplicate. After $24 \mathrm{~h}, 10 \mu \mathrm{l}$ DNR $(5 \mu \mathrm{g} / \mathrm{ml}$; Pfizer, Inc., New York, NY, USA) was added into the experimental, rabbit serum control and DNR groups, while $10 \mu 1$ RPMI-1640 medium was added to the blank group. Following a further 24 or $48 \mathrm{~h}$, the OD value in each well was measured using a multi-function enzyme-labeling at $450 \mathrm{~nm}$.

Cell cycle analysis. KG1a cells in the logarithmic growth phase were adjusted to a density of $5 \times 10^{5} / \mathrm{ml}$ and seeded in a 6 -well culture plate $(1 \mathrm{ml} /$ well $)$. The cells were divided into the 


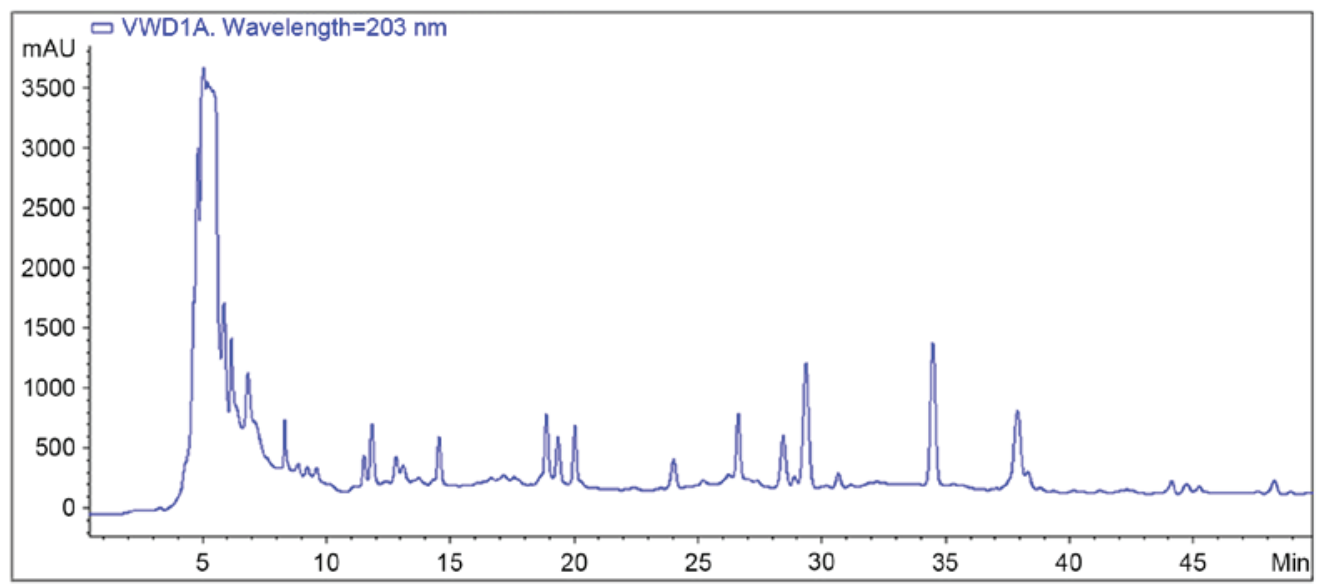

Figure 1. HPLC fingerprint analysis of YQYYT decoction. The HPLC system was equipped with an Agilent HP-1100 HPLC instrument. Separation was performed on an Agilent TC-18 (4.6x250 mm, $5 \mu \mathrm{m})$ analytical column with mobile phase consisting of acetonitrile and water with gradient elution at a flow rate of $0.6 \mathrm{ml} / \mathrm{min}$ and the column temperature at $25^{\circ} \mathrm{C}$. The UV wavelength used for detection was set at $203 \mathrm{~nm}$, and the analysis time was $50 \mathrm{~min}$. A total of 38 common peaks for YQYYT were identified in the HPLC fingerprint analysis. HPLC, high performance liquid chromatography; YQYYT, yi-qi-yang-yin-tang.

control group, high $(200 \mu \mathrm{l})$ and low $(100 \mu \mathrm{l})$ dose of YQYYT. After culturing for 24,48 and $72 \mathrm{~h}$, the cells were harvested by centrifugation (400 x g; $5 \mathrm{~min}$ ). Following the removal of the supernatant, the cells were washed twice with pre-cooled PBS and then stored at $-20^{\circ} \mathrm{C}$ overnight. Each sample was incubated with $0.5 \mathrm{ml}$ propidium iodide (Shanghai Megiddo Biological Pharmaceutical Co., Shanghai, China) in the dark for $30 \mathrm{~min}$. Cell cycle analysis was performed by flow cytometry (BD Accuri C6; BD Biosciences, Franklin Lakes, NJ, USA).

Cell sorting. KG1a cells were cultured in RPMI-1640 medium containing $10 \%$ fetal bovine serum, $100 \mathrm{U} / \mathrm{ml}$ penicillin and $100 \mathrm{U} / \mathrm{ml}$ streptomycin at $37^{\circ} \mathrm{C}$ under $5 \% \mathrm{CO}_{2}$ and saturated humidity. The cells were passaged every 2-3 days. The cells in the logarithmic growth phase were harvested. CD $34{ }^{+} \mathrm{CD} 38$ cells were sorted, and the purity of the resulting populations was determined by flow cytometry.

Reverse transcription-quantitative polymerase chain reaction $(R T-q P C R)$ analysis. The sorted $\mathrm{CD} 34^{+} \mathrm{CD} 38^{-} \mathrm{KG} 1$ cells were grouped and treated using the protocols as described previously. Total RNA was isolated using the RNA isolation kit (Kangwei Shiji, Biotechnology Co., Ltd., Beijing, China), and cDNA was prepared using the SuperRT cDNA Synthesis kit (Kangwei Shiji, Biotechnology Co., Ltd.). The following primers (Sangon Biotechnology, Shanghai, China) were used: $\beta$-actin forward, 5'-CCAAGGCCAACCGCGAGAAGATGA C-3' and reverse, 5'-AGGGTACATGGTGGTGCCGCCAGA C-3'; PTEN forward, 5'-ACCAGGACCAGAGGAAACCT-3' and reverse, 5'-GCTAGCCTCTGGATTTGACG-3'; Topo II $\alpha$ forward, 5'-GTGCGTGAAGTTGTGAATA-3' and reverse, 5'-GAGAGACACCAGAATTCAA-3'; mTOR forward, 5'-TAACGAGCTGGTCCGAATCA-3' and reverse, 5'-AGG GTGGACTTAGCTGGACT-3'. RT-qPCR was performed on the qPCR instrument (Applied Biosystems; Thermo Fisher Scientific, Inc.) with the SYBR-Green PCR kit (Beijing BioTake Biotechnology, Beijing, China). The optimized parameters for PCR were: $95^{\circ} \mathrm{C}$ for $2 \mathrm{~min}, 95^{\circ} \mathrm{C}$ for $15 \mathrm{sec}$, $60^{\circ} \mathrm{C}$ for $30 \mathrm{sec}$ and $72^{\circ} \mathrm{C}$ for $40 \mathrm{sec}(40$ cycles). The mean relative expression of PTEN, TopoII and mTOR in triplicate samples was calculated according to the $2^{-\Delta \Delta C \mathrm{C}}$ method (9).

Western blot analysis. The sorted $\mathrm{CD} 34^{+} \mathrm{CD} 38^{-} \mathrm{KG} 1$ cells were grouped and treated using the protocols as aforementioned. Proteins were extracted using RIPA lysis buffer (Beijing BioTake Corporation, Beijing, China), and protein concentration was determined using the Bradford method. Proteins $(20 \mu \mathrm{g})$ were separated by $10 \%$ SDS-PAGE and transferred onto polyvinylidene fluoride membranes using a semi-dry transfer method. The membranes were blocked with 5\% non-fat milk, and incubated with primary antibodies $(1: 3,000)$ overnight at $4^{\circ} \mathrm{C}$. After washing with TBST three times, the membranes were then incubated with secondary antibodies $(1: 1,000)$ for $1 \mathrm{~h}$ at room temperature. Proteins were detected using enhanced chemiluminescence kit and visualized under ultraviolet light. Primary antibodies: Anti-PTEN antibody (catalog no. ab32199; Abcam, Cambridge, UK), anti-topoisomerase II $\alpha$ antibody (catalog no. ab52934; Abcam), anti-mTOR antibody (catalog no. ab2732; Abcam). Secondary antibodies: Goat anti-rabbit IgG, horseradish peroxidase-conjugated (catalog no. CW0103S; Kangwei Shiji, Biotechnology Co., Ltd.).

Statistical analysis. Each experiment was repeated more than three times, and statistical analysis of data was performed using SPSS software (version 13.0; SPSS, Inc., Chicago, IL, USA). Data are expressed as the mean \pm standard deviation. Comparisons between two groups were analyzed using Student's t-test, and comparisons between different groups were analyzed by one-way analysis of variance test. $\mathrm{P}<0.05$ was considered to indicate a statistically significant difference.

\section{Results}

YQYYT-containing serum does not inhibit proliferation of KGla cells in vitro. As indicated in Table I, YQYYT-containing serum did not inhibit proliferation KGla cells at any of the doses tested at 24, 48 and $72 \mathrm{~h}$. 
Table I. Effect of YQYYT-containing serum at various concentrations on proliferation of KG1a cells.

\begin{tabular}{|c|c|c|c|c|c|}
\hline \multirow[b]{2}{*}{$\begin{array}{l}\text { Volume of YQYYT- } \\
\text { containing serum }(\mu 1)\end{array}$} & \multirow[b]{2}{*}{ Time (h) } & \multicolumn{2}{|c|}{ Control serum } & \multicolumn{2}{|c|}{ YQYYT-containing serum } \\
\hline & & $\begin{array}{l}\text { OD value, } \\
\text { mean } \pm \mathrm{SD}\end{array}$ & $\begin{array}{l}\text { Inhibition } \\
\text { rate }(\%)\end{array}$ & $\begin{array}{l}\text { OD value, } \\
\text { mean } \pm \mathrm{SD}\end{array}$ & $\begin{array}{l}\text { Inhibition } \\
\text { rate }(\%)\end{array}$ \\
\hline \multirow[t]{3}{*}{0} & 24 & $0.52 \pm 0.02$ & - & $0.51 \pm 0.01$ & - \\
\hline & 48 & $0.62 \pm 0.01$ & - & $0.64 \pm 0.01$ & - \\
\hline & 72 & $0.76 \pm 0.01$ & - & $0.81 \pm 0.02$ & - \\
\hline \multirow[t]{3}{*}{5} & 24 & $0.47 \pm 0.03$ & 8.3 & $0.47 \pm 0.02$ & 8.1 \\
\hline & 48 & $0.48 \pm 0.03$ & 12.7 & $0.57 \pm 0.01$ & 9.6 \\
\hline & 72 & $0.70 \pm 0.02$ & 7.6 & $0.73 \pm 0.01$ & 10.2 \\
\hline \multirow[t]{3}{*}{10} & 24 & $0.43 \pm 0.05$ & 16.1 & $0.45 \pm 0.03$ & 12.4 \\
\hline & 48 & $0.41 \pm 0.01$ & 14.8 & $0.56 \pm 0.04$ & 11.6 \\
\hline & 72 & $0.68 \pm 0.01$ & 9.3 & $0.69 \pm 0.01$ & 14.5 \\
\hline \multirow[t]{3}{*}{20} & 24 & $0.41 \pm 0.04$ & 20.3 & $0.42 \pm 0.03$ & 19.0 \\
\hline & 48 & $0.45 \pm 0.01$ & 24.8 & $0.53 \pm 0.02$ & 19.7 \\
\hline & 72 & $0.67 \pm 0.02$ & 11.7 & $0.68 \pm 0.03$ & 17.7 \\
\hline \multirow[t]{3}{*}{40} & 24 & $0.40 \pm 0.01$ & 20.9 & $0.41 \pm 0.01$ & $19.9^{a}$ \\
\hline & 48 & $0.45 \pm 0.01$ & 25.5 & $0.49 \pm 0.03$ & $23.5^{\mathrm{a}}$ \\
\hline & 72 & $0.62 \pm 0.02$ & 18.8 & $0.61 \pm 0.01$ & $24.3^{\mathrm{a}}$ \\
\hline
\end{tabular}

$\mathrm{n}=3$; ${ }^{\mathrm{a} P}>0.05$ vs. control group. SD, standard deviation; YQYYT, yi-qi-yang-yin-tang.

Combination of YQYYT-containing serum and DNR inhibits proliferation of KGla cells in vitro. To determine whether the YQYYT-containing serum increases the sensitivity of KG1a cells to DNR, the $\mathrm{IC}_{50}$ value of $\mathrm{DNR}$ for KG1a cells was determined using a previously described method (10). The $\mathrm{IC}_{50}$ value was indicated to be $5 \mu \mathrm{g} / \mathrm{ml}$ (data not shown).

The effects of the YQYYT-containing serum at different concentrations on the sensitivity of KG1a cells to DNR were subsequently examined using the $\mathrm{IC}_{50}$ value. At $24 \mathrm{~h}$, treatment with YQYYT-containing serum $(5,10,20$ and $40 \mu l$ in a total volume of $100 \mu \mathrm{l}$ ) and DNR did not inhibit the proliferation of KG1a cells compared with the group treated with DNR alone. However, when the volume of serum containing with YQYYT was increased to $40 \mu 1$, there was a significant inhibitory effect $(60.4 \%)$ compared with the DNR group on the growth of KG1a cells $(\mathrm{P}<0.05$; Table II). Following the treatment of DNR and YQYYT-containing serum (volume, 20 and $40 \mu \mathrm{l}$ ) for $48 \mathrm{~h}$, an inhibitory effect on KG1a cells was observed (58.9 and $72.5 \%$, respectively) compared with treatment with DNR alone (Table II). This inhibitory effect on proliferation was significant when the cells were treated with $40 \mu 1$ YQYYT-containing serum $(\mathrm{P}<0.01$; Table II). The rate of inhibition following the treatment with YQYYT-containing serum for $48 \mathrm{~h}(72.5 \%)$ was significantly higher compared with treatment for $24 \mathrm{~h}(60.4 \%, \mathrm{P}<0.01$; Table II). Taken together, these results indicated that the YQYYT-containing serum was able to promote the inhibitory effect of DNR on KG1a cells in a time- and dose-dependent manner.

YQYYT-containing serum promotes cell cycle progression of KGla cells from the $G_{0}$ phase. As shown in Tables III-V, YQYYT-containing serum was able to promote cell cycle progression of KG1a cells from the $G_{0}$ phase. The $G_{0} / G_{1}$ ratio was decreased and the percentage of $S$ and $G_{2} M$ phase cells was increased in a dose-dependent manner. However, there was no significant difference between the effects of treatment with 200 and $100 \mu \mathrm{l}$ YQYYT-containing serum.

The effect of YQYYT-containing serum on the $G_{0} / G_{1}$ ratio of the KGla cells was time-dependent, with a decreased proportion of cells in the $G_{0} / G_{1}$ phase following treatment for $72 \mathrm{~h}$ compared with the ratios following treatment for 24 and $48 \mathrm{~h}$. There were no significant differences in the proportion of $\mathrm{G}_{2} / \mathrm{M}$ cells between the control (24, 48 and $72 \mathrm{~h}$ ) and blank groups, or among the treatment groups at different time-points (24, 48 and 72 h). (Tables III-V).

CD $34^{+}$CD38- KGla cell subpopulation was isolated using an immunomagnetic cell sorting system. Following magnetic separation, the percentage of $\mathrm{CD} 34^{+} \mathrm{CD} 38^{-} \mathrm{KG} 1 \mathrm{a}$ cells was $99.2 \%$, which was significantly higher $(\mathrm{P}<0.01)$ compared with the percentage prior to sorting $(73.4 \%$, Fig. 2$)$. This phenotype was consistent with the biological characteristics of stem cells.

Effects of YQYYT-containing serum on the mRNA expression of PTEN, Topo II and mTOR in KGla cells. As shown in Fig. 3, PTEN gene expression was upregulated in KG1a cells when treated with DNR alone and in combination with YQYYT-containing serum compared with the blank group. The level of upregulation was significantly higher in KGla cells treated with a combination of DNR and serum containing YQYYT compared with the blank group $(\mathrm{P}<0.01)$.

The mRNA expression of Topo II was decreased in the DNR group, but was significantly increased in the group 
Table II. Effect of treatment with a combination of YQYYT-containing serum and DNR on proliferation of KG1a cells.

\begin{tabular}{|c|c|c|c|c|c|}
\hline \multirow[b]{2}{*}{ Groups } & \multirow[b]{2}{*}{ Time $(h)^{\mathrm{a}}$} & \multicolumn{2}{|c|}{ Control serum } & \multicolumn{2}{|c|}{ YQYYT-containing serum } \\
\hline & & $\begin{array}{l}\text { OD value, } \\
\text { mean } \pm \mathrm{SD}\end{array}$ & $\begin{array}{c}\text { Inhibition } \\
\text { rate }(\%)\end{array}$ & $\begin{array}{l}\text { OD value, } \\
\text { mean } \pm \mathrm{SD}\end{array}$ & $\begin{array}{c}\text { Inhibition } \\
\text { rate }(\%)\end{array}$ \\
\hline \multirow[t]{2}{*}{ Blank } & $24+24$ & $0.97 \pm 0.06$ & - & $1.01 \pm 0.05$ & - \\
\hline & $24+48$ & $1.35 \pm 0.01$ & - & $0.31 \pm 0.02$ & - \\
\hline \multirow[t]{2}{*}{ DNR } & $24+24$ & $0.52 \pm 0.01$ & 49.2 & $0.52 \pm 0.01$ & 48.6 \\
\hline & $24+48$ & $0.71 \pm 0.06$ & 46.8 & $0.67 \pm 0.04$ & 49 \\
\hline \multirow[t]{2}{*}{$5 \mu 1$ serum + DNR } & $24+24$ & $0.49 \pm 0.01$ & 46.7 & $0.50 \pm 0.01$ & 50.1 \\
\hline & $24+48$ & $0.74 \pm 0.04$ & 45.1 & $0.67 \pm 0.03$ & 48.5 \\
\hline \multirow{2}{*}{$10 \mu 1$ serum +DNR } & $24+24$ & $0.49 \pm 0.02$ & 48.8 & $0.48 \pm 0.02$ & 52.1 \\
\hline & $24+48$ & $0.76 \pm 0.05$ & 47.3 & $0.70 \pm 0.05$ & 56.5 \\
\hline \multirow[t]{2}{*}{$20 \mu 1$ serum +DNR } & $24+24$ & $0.48 \pm 0.03$ & 49.6 & $0.45 \pm 0.01$ & 53.9 \\
\hline & $24+48$ & $0.78 \pm 0.04$ & 43.3 & $0.54 \pm 0.02$ & $58.9^{\mathrm{a}}$ \\
\hline \multirow[t]{2}{*}{$40 \mu 1$ serum +DNR } & $24+24$ & $0.51 \pm 0.02$ & 50.6 & $0.40 \pm 0.01$ & $60.4^{\mathrm{a}}$ \\
\hline & $24+48$ & $0.69 \pm 0.02$ & 48.8 & $0.37 \pm 0.03$ & $72.5^{\mathrm{b}}$ \\
\hline
\end{tabular}

$\mathrm{n}=3 ;$ a $\mathrm{P}<0.05$ vs. DNR group; ${ }^{\mathrm{P}} \mathrm{P}<0.01$ vs. DNR group. DNR, daunorubicin; OD, optical density; SD, standard deviation; YQYYT, yi-qi-yang-yin-tang. ${ }^{a}$ The first number refers to the duration of treatment with the control serum and the second number refers to the duration of treatment with the YQYYT-containing serum.

Table III. Effect of YQYYT-containing serum on cell cycle of KG1 a cells following $24 \mathrm{~h}$ treatment.

\begin{tabular}{lccr}
\hline Group & $\mathrm{G}_{0} / \mathrm{G}_{1}(\%)$ & $\mathrm{S}(\%)$ & $\mathrm{G}_{2} / \mathrm{M}(\%)$ \\
\hline Blank & $84.07 \pm 1.63$ & $8.96 \pm 2.01$ & $7.14 \pm 3.39$ \\
Control & & & \\
$100 \mu \mathrm{l}$ & $82.52 \pm 2.31$ & $12.10 \pm 1.37$ & $9.17 \pm 4.41$ \\
$200 \mu \mathrm{l}$ & $81.15 \pm 2.45$ & $12.57 \pm 3.11$ & $9.48 \pm 2.27$ \\
Treatment & & & \\
$100 \mu 1$ & $77.81 \pm 2.05$ & $10.68 \pm 3.01$ & $11.24 \pm 1.24$ \\
$200 \mu 1$ & $76.50 \pm 2.33^{\mathrm{a}}$ & $14.41 \pm 1.64^{\mathrm{a}}$ & $9.19 \pm 2.15$ \\
\hline
\end{tabular}

$\mathrm{n}=3 ;{ }^{\mathrm{a}} \mathrm{P}<0.05$ vs. blank group. Data are expressed as the mean \pm standard deviation. YQYYT; yi-qi-yang-yin-tang.

Table V. Effect of YQYYT-containing serum on cell cycle of KG1a cells following $72 \mathrm{~h}$ treatment.

\begin{tabular}{lccc}
\hline Group & $\mathrm{G}_{0} / \mathrm{G}_{1}(\%)$ & $\mathrm{S}(\%)$ & $\mathrm{G}_{2} / \mathrm{M}(\%)$ \\
\hline Blank & $77.20 \pm 1.87$ & $12.27 \pm 2.61$ & $8.73 \pm 3.12$ \\
Control & & & \\
$100 \mu 1$ & $74.15 \pm 1.95$ & $16.16 \pm 1.73$ & $9.68 \pm 2.56$ \\
$200 \mu 1$ & $72.81 \pm 2.72$ & $18.27 \pm 3.28$ & $6.92 \pm 2.11$ \\
Treatment & & & \\
$100 \mu 1$ & $62.94 \pm 1.49^{\mathrm{a}}$ & $25.23 \pm 1.80$ & $11.83 \pm 1.79$ \\
$200 \mu 1$ & $59.33 \pm 1.81^{\mathrm{b}}$ & $27.77 \pm 1.35^{\mathrm{b}}$ & $12.90 \pm 2.93$ \\
\hline
\end{tabular}

$\mathrm{n}=3$; ${ }^{\text {a }} \mathrm{P}<0.05$ vs. blank group; ${ }^{\mathrm{b}} \mathrm{P}<0.01$ vs. blank group. Dataare expressed as the mean \pm standard deviation. YQYYT; yi-qi-yang-yin-tang.
Table IV. Effect of YQYYT-containing serum on cell cycle of KG1a cells following $48 \mathrm{~h}$ treatment.

\begin{tabular}{lccr}
\hline Group & $\mathrm{G}_{0} / \mathrm{G}_{1}(\%)$ & $\mathrm{S}(\%)$ & $\mathrm{G}_{2} / \mathrm{M}(\%)$ \\
\hline Blank & $82.10 \pm 2.01$ & $8.90 \pm 0.99$ & $9.10 \pm 1.73$ \\
Control & & & \\
$100 \mu \mathrm{l}$ & $83.53 \pm 1.31$ & $6.20 \pm 2.76$ & $10.30 \pm 1.81$ \\
$200 \mu \mathrm{l}$ & $81.90 \pm 2.35$ & $9.50 \pm 2.70$ & $8.60 \pm 1.92$ \\
Treatment & & & \\
$100 \mu \mathrm{l}$ & $75.44 \pm 1.88$ & $13.80 \pm 2.25$ & $11.80 \pm 2.43$ \\
$200 \mu \mathrm{l}$ & $72.71 \pm 3.26^{\mathrm{a}}$ & $15.13 \pm 1.56^{\mathrm{a}}$ & $10.22 \pm 2.35$ \\
& & &
\end{tabular}

$\mathrm{n}=3$; ${ }^{\mathrm{a}} \mathrm{P}<0.05$ vs. blank group. Data are expressed as the mean \pm standard deviation. YQYYT; yi-qi-yang-yin-tang.

treated with the combination of DNR and YQYYT-containing serum $(\mathrm{P}<0.01)$, when compared with the blank group.

The mRNA expression of mTOR was decreased in the DNR group, but was increased in the group treated with the combination of DNR and serum containing YQYYT when compared with the blank group (Fig. 3).

Effects of YQYYT-containing serum on the protein expression of PTEN, Topo II and mTOR in KGla cells. The blank group was used as the standard group (relative quantitative value of 1), and the relative quantitative values of each group were calculated using Image Lab 4.0 software (Bio-Rad Laboratories, Inc., Hercules, CA, USA). Compared with the blank group, the expression of PTEN protein in the DNR group and the group treated with a combination of DNR and serum-containing YQYYT increased, the mTOR protein levels in the group 


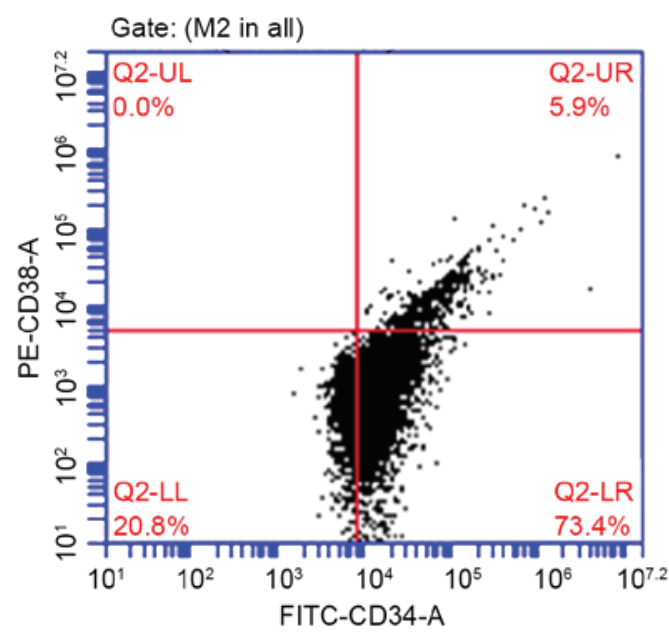

B

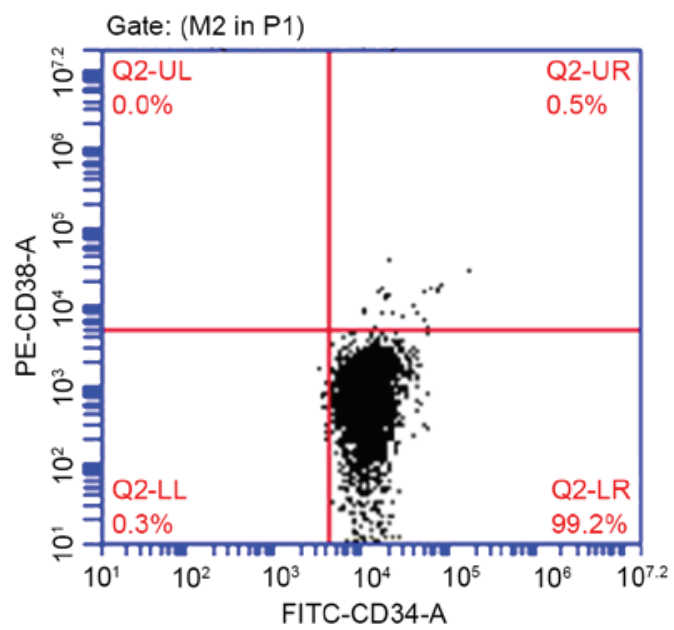

Figure 2. Percentage of CD34+CD38 KGla cells (A) prior to and (B) following cell sorting. CD, cluster of differentiation; FITC, fluorescein isothiocyanate; $\mathrm{PE}$, phycoerythrin.

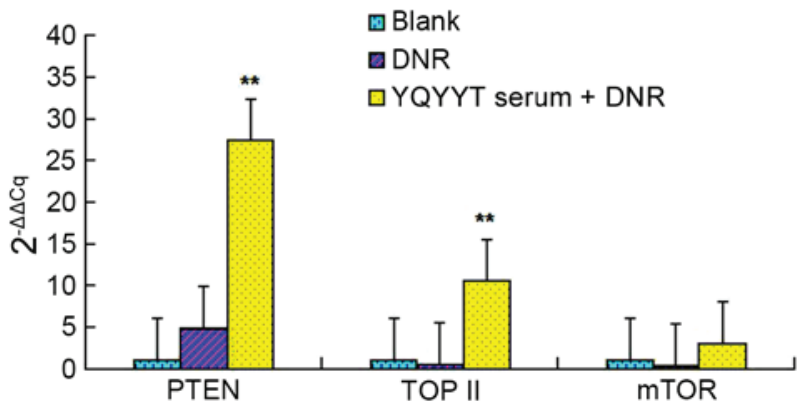

Figure 3. Effects of YQYYT-containing serum on the mRNA expression of PTEN, Topo II and mTOR in KG1a cells. $n=3,{ }^{* *} \mathrm{P}<0.01$ vs. blank group. DNR daunorubicin; mTOR, mechanistic target of rapamycin; PTEN, phosphatase and tensin homolog; Topo II, topoisomerase II; YQYYT; yi-qi-yang-yin-tang.

treated with a combination of DNR and serum containing YQYYT decreased significantly (Table VI; Fig. 4). In the DNR group, the level of Topo II protein was downregulated compared with the blank group, while the level of Topo II was upregulated in the group treated with a combination of DNR and YQYYT-containing serum (Table VI; Fig. 4).

\section{Discussion}

Acute leukemia is a type of malignant cancer for which long-term disease-free survival can be potentially achieved through chemotherapy (11). Although the current induction therapy achieves complete remission (CR) in $80 \%$ of patients, $>60 \%$ of patients become resistant to chemotherapy and even relapse (12). Although LSCs, which express high levels of $\mathrm{CD} 34^{+}, \mathrm{CD} 38^{-}$and $\mathrm{CD} 123^{+}$, represent only a small subpopulation of cells in patients with acute myeloid leukemia (AML) (13), these cells appear to be the cause of drug resistance and relapse $(14,15)$.

Due to untargeted toxicity, chemotherapy drugs not only kill leukemia cells, but also induce damage of normal tissues and cells to various degrees. This result in impaired proliferation, differentiation and maturation of HSCs or progenitor cell, and induces potentially life-threatening effects, including bone marrow suppression, pancytopenia, low immunity and increased susceptibility to infection (16). Recent studies showed that many novel markers, including C-type lectin-like molecule-1 (CLL-1), CD96, T cell immunoglobulin mucin 3, CD47, CD32 and CD25, are expressed by $\mathrm{CD} 34^{+} \mathrm{CD} 38^{-}$LSCs, but not by HSCs. Therefore, these markers have been used to confirm the presence of LSCs in patients in clinical studies $(17,18)$. Tettamanti et al (19) indicated that the combination of anti-CD123 antibody and chimeric antigen receptor-integrated cytokines induced cytotoxic T cells that efficiently eliminated LSCs. Additional reports demonstrated that the incidence of biphenotypic acute leukemia (BAL) is between 1.3-8\%, and BAL cells are derived from multipotent progenitor cells (20). During the development of leukemia, multipotent progenitor cells can differentiate into myeloid and lymphoid leukemia cells, and these patients with BAL are associated with poor prognosis. Furthermore, the expression of CD34 is negatively correlated with therapeutic efficacy in BAL (21). It was observed that the rate of expression of the LSC immunological markers, CD123 and CD47, as well as CLL-1 and CD96, reached $100 \%$ and $>60 \%$, respectively (22). These markers can be used to improve the identification and elimination of LSCs. Song et al (23) identified CD44 as an important target for LSC therapy, and CD44 monoclonal antibodies can induce the differentiation and inhibit proliferation of primary leukemia cells, as well as effectively promoting programmed cell death of leukemia cells.

The capacity of LSCs for self-renewal is closely associated with the regulation of the cell cycle, which is also closely linked with DNA damage and repair. These processes are important for survival of LSCs when treated with DNA-damaging agents (24). It has been demonstrated that $>95 \%$ of LSCs are in the $\mathrm{G}_{0}$ phase (25), where they do not proliferate and have a low ability for replication. In the $\mathrm{G}_{0}$ phase, the cells have an infinite ability for self-renewal and are not sensitive to chemotherapy. Therefore, the cells in the $\mathrm{G}_{0}$ phase can easily evade the destructive effects of 
Table VI. Image Lab 4 software analysis of the relative quantitative values of western blot analysis of PTEN, Topo II and mTOR.

\begin{tabular}{lccc}
\hline Group & PTEN & mTOR & Topo II \\
\hline Blank & 1 & 1 & 1 \\
Control & $1.62 \pm 0.23^{\mathrm{a}}$ & $0.93 \pm 0.12$ & $0.62 \pm 0.19^{\mathrm{a}}$ \\
Treatment & $2.17 \pm 0.34^{\mathrm{a}}$ & $0.33 \pm 0.11^{\mathrm{a}}$ & $1.74 \pm 0.18^{\mathrm{a}}$ \\
\hline
\end{tabular}

$\mathrm{n}=3$; ${ }^{\mathrm{P}}<0.05$ vs. blank group. Data are expressed as the mean \pm standard deviation. DNR, daunorubicin; mTOR, mechanistic target of rapamycin; PTEN, phosphatase and tensin homolog; Topo II, topoisomerase II; YQYYT; yi-qi-yang-yin-tang.

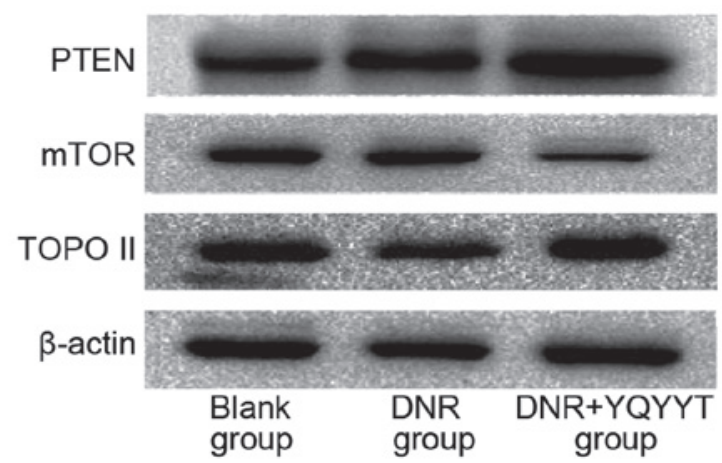

Figure 4. Western blot analysis of PTEN, Topo II and mTOR. DNR, daunorubicin; mTOR, mechanistic target of rapamycin; PTEN, phosphatase and tensin homolog; Topo II, topoisomerase II; YQYYT; yi-qi-yang-yin-tang.

chemotherapeutic agents (26). Drugs which specifically target the cell cycle, particularly 5-fluorouracil, methotrexate and cytarabine antimetabolite, are not effective against LSCs (27). Saito et al (28) reported that $\mathrm{G}_{0}$ phase AML-LSC in the endosteum can be induced to enter the cell cycle by granulocyte colony-stimulating factor, with apoptosis and elimination of LSCs being enhanced by combination therapy with cell cycle-dependent chemotherapeutic drugs (28). Song et al (29) investigated the effects of Zuigui pill, Yougui pill and their disassembled prescriptions on the cell cycle progression of bone marrow mesenchymal stem cells (BMSCs) which are involved in osteogenic differentiation, and reported that Zuigui pill and YQYYT were able to significantly promote proliferation of BMSCs, and alter the cell cycle and apoptosis of BMSCs (29). In the present study, it was detected that treatment with YQYYT-containing serum promoted cell cycle progression of KG1a cells, therefore indicating that treatment with YQYYT increases the sensitivity of leukemia cells to chemotherapeutic agents and enhances the chemotherapeutic response. In this way, not only can drug resistance be inhibited, residual LSCs can also be eliminated, therefore greatly reducing the possibility of disease recurrence.

PTEN is a highly conserved tumor suppressor gene, which can inhibit cancer cell proliferation, induce apoptosis and cell cycle arrest, simultaneously regulate a variety of molecules, and reduce tumor invasiveness (30) It is currently accepted that PTEN inhibits cancer cell growth, infiltration, invasiveness and metastasis via inhibition of multiple signal transduction pathways (31). However, although PTEN gene deficiency leads to the generation and proliferation of LSCs, it does not affect differentiation and survival of HSCs (32). Therefore, this indicates that targeting PTEN may be a potential strategy for LSC-targeted therapy. In addition, the PTEN gene can inhibit mTOR activity by negatively regulating the PI3K/Akt signaling pathway, therefore inhibiting cancer cell proliferation, promoting apoptosis and reversing multidrug resistance (7). Furthermore, it has been previously demonstrated that overexpression of PTEN can slow disease progression and prolong the survival of leukemic mice (33). Using RT-PCR techniques, Xu et al (34) reported that YQYYT is able to decrease the mRNA expression of Fms related tyrosine kinase 3 and $\mathrm{N}$-ras in bone marrow mononuclear cells in patients with AML, inhibit proliferation of leukemic cells in patients with AML and exhibits a therapeutic effect on AML (34). In the present study, it was observed that treatment of KG1a cells with YQYYT-containing serum was able to increase PTEN expression of RNA or protein.

Topoisomerase has an important role in DNA replication, transcription, repair and recombination (35). Topo II is an enzyme that acts on the topology of DNA and regulates changes in the conformation of DNA (36). Changes in the quality and quantity of Topo II would directly affect binding between chemotherapeutic drugs and DNA, which would lead to a decrease in drug-induced cleavage complex formation and result in the induction of drug resistance. The majority of LSCs express low levels of Topo II, and the upregulation of Topo II expression and activity increases sensitivity to anthracycline (37). Shi et al (38) reported that Six Spirits pill, a Chinese traditional medicine, was able to reverse multidrug resistance in leukemia cells by reducing the expression of p170 and increasing the expression of Topo II $\beta$ (38). Kim et al (39) observed that ginsenoside Rg3 and verapamil were able to increase the sensitivity of multidrug resistant leukemia cells to chemotherapeutic drugs, and a limited number of side-effects were detected (39). In the present study, it was observed that treatment of KG1a cells with YQYYT-containing serum was able to increase Topo II expression of RNA or protein.

Chinese herbal formulae are flexible, with a variety of regulatory mechanisms and multiple targets for anti-cancer effects that may significantly reduce the damage induced by chemotherapeutic drugs. Therefore, Chinese herbal agents may have an important role in increasing the efficacy of chemotherapy in the clinical treatment of leukemia, as well as reducing toxicity and reversing drug resistance $(40,41)$. Yan and Shi (42) reported that the clinical efficacy of combination chemotherapy with YQYYT and refractory acute leukemia (RAL) is higher compared with the efficacy achieved with conventional chemotherapy alone, with limited side effects. This effect on efficacy may be associated with the promotion of cell cycle progression of leukemia cells by YQYYT (42).

The results showing the effects of YQYYT-containing serum on cell cycle progression and the expression of resistance-associated genes in KG1a cells are preliminary and require further investigation in in vivo studies. Furthermore, 
changes in cell cycle of tumor cells are regulated by multiple proteins and cytokines, and further studies are necessary to reveal the detailed mechanisms underlying these processes. However, these results indicate the potential of YQYYT in enhancing the sensitivity of LSC to DNR chemotherapy.

\section{References}

1. Hu Y and Li S: Survival regulation of leukemia stem cells. Cell Mol Life Sci 73: 1039-1050, 2016.

2. Passegué E and Weisman IL: Leukemic stem cells: Where do they come from? Stem Cell Rev 1: 181-188, 2005.

3. Styczynski J and Drewa T: Leukemic stem cells: From metabolic pathways and signaling to a new concept of drug resistance targeting. Acta Biochim Pol 54: 717-726, 2007.

4. Guzman ML, Neering SJ, Upchurch D, Grimes B, Howard DS, Rizzieri DA, Luger SM and Jordan CT: Nuclear factor-kappaB is constitutively activated in primitive human acute myelogenous leukemia cells. Blood 98: 2301-2307, 2001

5. Won EJ, Kim HR, Park RY, Choi SY, Shin JH, Suh SP, Ryang DW, Szardenings M and Shin MG: Direct confirmation of quiescence of CD34+CD38-leukemia stem cell populations using single cell culture, their molecular signature and clinicopathological implications. BMC Cancer 15: 217, 2015.

6. Irons RD and Stillman WS: Cell proliferation and differentiation in chemical leukemogenesis. Stem Cells 11: 235-242, 1993.

7. Peng C, Chen Y, Li D and Li S: Role of Pten in leukemia stem cells. Oncotarget 1: 156-160, 2010.

8. MacDonald TL, Labroli MA and Tepe JJ: 7.16 - DNA Topoisomerase Inhibitors. In: Comprehensive Natural Products Chemistry. Vol 7. Elsevier Ltd., Philadelphia, PA, pp593-614, 1999.

9. Livak KJ and Schmittgen TD: Analysis of relative gene expression data using real-time quantitative PCR and the 2(-Delta Delta C(T)) method. Methods 25: 402-408, 2001.

10. He K, Yu P, Xing HY, Li Y, Tian Z, Wang M, Tang KJ and Rao Q: Resistance of leukemia KGla cells with positive N-cadherin in phase $\mathrm{G}(0)$ against killing activity of VP16. Zhongguo Shi Yan Xue Ye Xue Za Zhi 19: 1102-1106, 2011 (In Chinese).

11. Colado E, Paino T, Maiso P, Ocio EM, Chen $X$, Alvarez-Fernández S, Gutiérrez NC, Martín-Sánchez J, Flores-Montero J, San Segundo L, et al: Zalypsis has in vitro activity in acute myeloid blasts and leukemic progenitor cells through the induction of a DNA damage response. Haematologica 96: 687-695, 2011.

12. Döhner H, Estey E, Grimwade D, Amadori S, Appelbaum FR, Büchner T, Dombret H, Ebert BL, Fenaux P, Larson RA, et al: Diagnosis and management of AML in adults: 2017 ELN recommendations from an international expert panel. Blood 129. 424-447, 2017.

13. Vergez F, Green AS, Tamburini J, Sarry JE, Gaillard B, Cornillet-Lefebvre P, Pannetier M, Neyret A, Chapuis N, Ifrah N, et al: High levels of CD34+CD38low/-CD123+ blasts are predictive of an adverse outcome in acute myeloid leukemia: A Groupe Ouest-Est Des Leucemies Aigues et maladies du sang (GOELAMS) study. Haematologica 96: 1792-1798, 2011.

14. She M, Niu X, Chen X, Li J, Zhou M, He Y, Le Y and Guo K: Resistance of leukemic stem-like cells in AML cell line KGla to natural killer cell-mediated cytotoxicity. Cancer Lett 318: 173-179, 2012.

15. Long J, Liu S, Li K, Zhou X, Zhang P and Zou L: High proportion of CD34+/CD38-cells is positively correlated with poor prognosis in newly diagnosed childhood acute lymphoblastic leukemia. Leuk Lymphoma 55: 611-617, 2014.

16. Sohl SJ, Schnur JB and Montgomery GH: A meta-analysis of the relationship between response expectancies and cancer treatment-related side effects. J Pain Symptom Manage 38: 775-784, 2009.

17. Horton SJ and Huntly BJ: Recent advances in acute myeloid leukemia stem cell biology. Haematologica 97: 966-974, 2012.

18. Chávez-González A, Dorantes-Acosta E, Moreno-Lorenzana D, Alvarado-Moreno A, Arriaga-Pizano L and Mayani H: Expression of CD90, CD96, CD117, and CD123 on different hematopoietic cell populations from pediatric patients with acute myeloid leukemia. Arch Med Res 45: 343-350, 2014.
19. Tettamanti S, Biondi A, Biagi E and Bonnet D: CD123 AML targeting by chimeric antigen receptors: A novel magic bullet for AML therapeutics? Oncoimmunology 3: e28835, 2014.

20. Yu L, Reader JC, Chen C, Zhao XF, Ha JS, Lee C, York T, Gojo I, Baer MR and Ning Y: Activation of a novel palmitoyltransferase ZDHHC14 in acute biphenotypic leukemia and subsets of acute myeloid leukemia. Leukemia 25: 367-371, 2011.

21. Zulfikar O, Koc B and Kebudi R: The oue center experience. J Clin Oncol 31: 136-139, 2013.

22. Majeti R: Monoclonal antibody therapy directed against human acute myeloid leukemia stem cells. Oncogene 30: 1009-1019, 2011.

23. Song QX, Wu Y and Chen YZ: The effect of CD44 antibody-HI44a on proliferation and differentiation of HL-60 cells. Chine Pharmacol Bulletin 3: 22, 2011.

24. Misaghian N, Ligresti G, Steelman LS, Bertrand FE, Bäsecke J, Libra M, Nicoletti F, Stivala F, Milella M, Tafuri A, et al: Targeting the leukemic stem cell: The holy grail of leukemia therapy. Leukemia 23: 25-42, 2009.

25. Hope KJ, Jin L and Dick JE: Human acute myeloid leukemia stem cells. Arch Med Res 34: 507-514, 2003.

26. Pollyea DA, Gutman JA, Gore L, Smith CA and Jordan CT: Targeting acute myeloid leukemia stem cells: A review and principles for the development of clinical trials. Haematologica 99: 1277-1284, 2014.

27. Wang $\mathrm{C}$ and Chen $\mathrm{Y}$ : The study of molecular mechanism of leukemia stem cell resistance. J Mol Diagno Ther 3: 203-206, 2009.

28. Saito Y, Uchida N, Tanaka S, Suzuki N, Tomizawa-Murasawa M, Sone A, Najima Y, Takagi S, Aoki Y, Wake A, et al: Induction of cell cycle entry eliminates human leukemia stem cells in a mouse model of AML. Nat Biotechnol 28: 275-280, 2010.

29. Song N, He WZ, Wang ZM and Ren YL: Effects of serum containing Zuigui pill, Yougui pill and their disassembled prescriptions on the cell cycle and cell apoptosis of bone marrow mesenchymal stem cells in osteogenic differentiation. Chin J Trad Chin Med Pharm 5: 77, 2013.

30. Wu H, Goel V and Haluska FG: PTEN signaling pathways in melanoma. Oncogene 22: 3113-3122, 2003.

31. Morotti A, Panuzzo C, Crivellaro S, Carrà G, Torti D, Guerrasio A and Saglio G: The Role of PTEN in myeloid malignancies. Hematol Rep 7: 5844, 2015.

32. Cheung AM and Mak TW: PTEN in the haematopoietic system and its therapeutic indications. Trends Mol Med 12: 503-505, 2006.

33. Peng C, Chen Y, Yang Z, Zhang H, Osterby L, Rosmarin AG and Li S: PTEN is a tumor suppressor in CML stem cells and BCR-ABL-induced leukemias in mice. Blood 115: 626-635, 2010.

34. Xu R, Wang X and Wang J: Study on the expression of Flt 3 and $\mathrm{N}$-ras genes human leukemia stem cells using RT-PCT. Zhe Int Trad Chin West Med 5: 278-280, 2009.

35. Cowell IG and Austin CA: Mechanism of generation of therapy related leukemia in response to anti-topoisomerase II agents. Int J Environ Res Public Health 9: 2075-2091, 2012.

36. Wang JC and Kirkegaard K: DNA topoisomerases. Gene Amplif Anal 2: 455-473, 1981

37. Liu MY, Wang WZ, Liao FF, Wu QQ, Lin XH, Chen YH, Cheng L, Jin XB and Zhu JY: Selective and effective targeting of chronic myeloid leukemia stem cells by topoisomerase II inhibitor etoposide in combination with imatinib mesylate in vitro. Cell Biol Int 41: 16-23, 2017.

38. Shi $\mathrm{Z}$ and Yang W: The effect and underlying mechanism of liushenpill in reversing multidrug resistance in leukemia cells. J Tian Uni Trad Chin Med 1: 11-13, 2007.

39. Kim SS, Seong S and Kim SY: Synergistic effect of ginsenoside $\mathrm{Rg} 3$ with verapamil on the modulation of multidrug resistance in human acute myeloid leukemia cells. Oncol Lett 7: 1265-1269, 2014.

40. Li J and Liu XB: Advances in medicine of toxicity and synergistic effects in cancer treatment. J Pharmaceut Res 4: 229-231, 2015.

41. Long X, Geng Y and Guo Q: Recent progress in anti-tumor medicine and the role of the active ingredients in recent years. Chin Arch Tradl Chin Med 4: 862-864, 2015.

42. Yan L and Shi Z: Clinical study on reversal of multidrug resistance in refractory acute leukemia by Supplementing qi and nourishing yin. J Beij Uni Trad Chin Med 1: 68-72, 2015. 